\title{
Some Fundamental Issues in Geoethics
}

\author{
DAVID M. ABBOTT, JR.* \\ AIPG Ethics Committee Chairman, Denver, Colorado, USA \\ dmageol@msn.com
}

\begin{abstract}
Ethics and morals concern themselves with distinguishing right from wrong, with actions, and with the volition involved. Dictionaries define "ethics" in terms of "morals" and "morals" in terms of "ethics," so the terms are quite similar and circular. I define "morals" as informal statements and "ethics" as written statements adopted by some group. General morals apply to everyone while professional ethics generally apply only to members of a particular profession. Moral and ethical analysis requires careful and consistent discrimination of the relevant facts. It is important to remember that moral/ethical analysis does not resolve all questions because different people rank morallethical values differently. We must respectfully agree to disagree. Morallethical rules apply to all persons at all times. However, exceptions are allowed following careful analysis of the exception. For example, surgeons are allowed to cut people open, most of us are not allowed to do so. Morallethical aspirations are statements encouraging a particular activity but no demerits follow from choosing to follow one aspiration and not another. Continuing professional development (CPD) provides an example. Geoscience ethics codes all recommend CPD, which is aspirational. For those societies that require some minimum amount of CPD, an aspiration has become a rule. Honesty is the principal geoscience ethical rule. Some geoscience societies have disciplinary procedures, most do not; nor should they. Disciplinary procedures must allow for due process and appropriate confidentiality until resolved.
\end{abstract}

\section{BASICS OF MORALITY AND ETHICS}

$\mathrm{B}$ ecause dictionary definitions of "morals" and "ethics" tend to define one term using the other, a circular argument, I define morals as informal statements about what people are expected to do and ethics as written statements prepared by some group like a geoscience society that describe the conduct expectations for members of the issuing group. Discussions of geoscience ethics or geoethics should be grounded in general morality. Bernard Gert (2004) provided the best summary for the general reader of general morality. Rather than formulating a new ethical statement or system, Gert examined the informal moral principles on which all societies we know about agree. Gert points out that that there are two kinds of moral statements: moral rules and moral aspirations or ideals.

Moral rules must be obeyed by all people with respect to all other people all the time. Gert identifies ten fundamental moral rules that everyone recognizes regardless of whether they had been formally articulated or written down within their group, culture, or society. They are:

1. Do not kill.

6. Do not deceive.

2. Do not cause pain or injury.

7. Keep your promises.

3. Do not disable.

4. Do not deprive of freedom.

8. Do not cheat or violate rules of conduct.

5. Do not deprive of 9. Obey the law - inpleasure/the pursuit of happiness.

Do not deceive is emphasized because I believe that honesty is the basic moral principle underlying all geoscience ethics codes (Abbott, 2004). I also added "the pursuit of happiness" to Gert's "Do not deprive of pleasure" rule because I feel that pursuit of happiness better captures the concept of Gert's rule.

Moral aspirations or ideals are admirable activities that some people engage in some of the time but which are not obligatory on everyone all the time. For example, none of us individually can relieve hunger worldwide even if we 
choose to work towards that goal. Actions reflecting moral aspirations or ideals include such things as contributing to the cure of some disease, working to ease hunger. Within a geoscience setting, actions reflecting moral aspirations or ideals may include volunteering for a professional association, writing papers, giving presentations at professional meetings, and engaging in public outreach about matters that are within our areas of expertise such as natural hazards or the responsible development of natural resources. While promoting a moral aspiration warrants recognition, demerits are not given if one does not work towards one or more moral aspirations.

Continuing professional development (CPD) provides an example of geoscience activities that are sometimes aspirational and sometimes rules. Geoscience codes of ethics or conduct usually contain a statement encouraging continuing education; an aspirational statement. However, increasing numbers of geoscience organizations are requiring at least some members to engage in a specified minimum amount of CPD. For these organizations, CPD has become an ethical rule for the specified membership classes.

Gert (2004) also recognizes that there are exceptions to the moral rules. For example, selfdefense is a generally recognized exception to the "Do not kill" rule. Similarly, surgeons are allowed to cut into a patient's abdomen as part of a surgical procedure in violation of the "Do not cause pain or injury" rule. Gert provides a checklist for identifying a morally justified violation of a moral rule:

- What moral rule is involved?

- Who is harmed?

- What harm is avoided by the violation?

- Can everyone violate the rule in the same way?

- Is some sort of emergency involved?

- Was the violation intentional?

- Was coercion involved?

- Are you willing to publicly acknowledge and accept the consequences of the violation? (Integrity).

"Integrity" was parenthetically added to Gert's checklist because publicly acknowledging and accepting the consequences of a violation of a moral rule (or a law) is where integrity enters the discussion. Stephen L. Carter (1996) notes that "Integrity is like the weather: everybody talks about it but nobody knows what to do about it. ...[I]ntegrity is like good weather, because everybody is in favor of it." Carter defines integrity as requiring three steps:

(1) discerning what is right and what is wrong;

(2) acting on what you have discerned, even at personal cost; and

(3) saying openly that you are acting on your understanding of right from wrong.

The first criterion captures the idea of integrity as requiring a degree of moral reflectiveness. The second brings in the idea of an integral person as steadfast, which includes the sense of keeping commitments. The third reminds us that a person of integrity is unashamed of doing right. The word [integrity] conveys not so much a single-mindedness as a completeness; not the frenzy of a fanatic who wants to remake all the world in a single mold, but the serenity of a person who is confident in the knowledge that he or she is living rightly.

Honesty is a basic geoscience ethical principle (Abbott, 2002 and 2004). Demonstrating the reliability of sampling results through the use of Quality Assurance/Quality Control (QA/QC) procedures has become required practice in the mining industry in recent years and should be applied to any sampling program (Abbott, 2007 \& 2016a). Such QA/QC procedures appear to violate the honesty principle by concealing the identity of the standard, duplicate, and blank $\mathrm{QA} / \mathrm{QC}$ samples in a sample stream from those further down the sample preparation and analysis procedures performance line. But is this apparent violation unethical, or is it actually necessary to assure the validity of scientific results? Using Gert's rules for identifying a morally justified exception to a rule for $\mathrm{QA} / \mathrm{QC}$ samples results in:

- Rule being violated: do not deceive.

- Harm done: increased analytical costs.

- Harm avoided: determining and verifying the reliability of your sampling and analytical processes. 
- Everyone can and should be using QA/QC procedures in data collection.

- Although the identity of the standards, blanks, and duplicates should be hidden, their existence need not be.

Gert (2004) makes another very important point about moral or ethical analysis: such analysis will not answer all moral/ethical questions. Different people rank moral or ethical principles differently in their analysis of a particular situation and thus can arrive at opposing moral/ethical conclusions each have a valid moral/ethical justification. Common examples include abortion and capital punishment. Most geoscience ethics codes require geoscientists to maintain the confidentiality of their employer's or client's confidential information. However, most geoscience ethics codes also state that protection of the public's health, safety, and welfare (including financial welfare) is the highest duty or responsibility of members. By stating that this obligation is "the highest duty or responsibility," these codes place the public's health, safety, and welfare above employer or client confidentiality. Geoscientists should bring confidential evidence of fraud, environmental degradation, or a geohazard situation to the attention of appropriate authorities (When one is faced with a conflict between confidentiality and disclosing a potential public harm, one should proceed very carefully and seek the advice of knowledgeable, independent parties for advice).

The EFG's (European Federation of Geologists) Code of Ethics (2016) states this principle:

$\ldots$

8. The geologist must avoid any sort of negligence in the practice of his/her profession, especially when this gives rise to risks or of material or moral damage for his/her client or for the environment.

9. The geologist must not alter, or deny the existence of, facts or accepted technical or scientific truths which could thereby favour a client or mislead the public.

10. The geologist must not promise or broadcast specific professional advice that cannot be supported by a genuine, objective possibility, ...
10.2 If, after having given his/her advice, a geologist becomes aware that it will not be entirely followed, he/she should, regardless of his/her own position, inform the relevant person of the foreseen risks....

\section{TO WHOM DO ETHICS CODES APPLY?}

Gert (2004) also points out that it is important to determine who or what is covered by a moral or ethical statement. Geoscience ethics codes apply specifically to covered member categories of the issuing geoscience society. Other codes, such as the 2015 American Geoscience Institute Guidelines for Ethical Professional Conduct (2015 AGI Guidelines) assert a broader reach. The 2015 AGI Guidelines begin, "These guidelines address common ethical topics across the geoscience community; the ethics statements of individual societies may expand beyond these guidelines" clearly extending the application of the Guidelines to everyone in the geoscience community regardless of their membership in an AGI member society. The Ethical Guidelines for Statistical Practice issued by the American Statistical Association (2016) go even further by explicitly stating, "Because society depends on informed judgments supported by statistical methods, all practitioners of statistics, regardless of training and occupation or job title, have an obligation to work in a professional, competent, and ethical manner and to discourage any type of professional and scientific misconduct." At least according to the American Statistical Association, their Ethical Guidelines for Statistical Practice apply to all geoscientists using statistical analysis.

This brings up the important point: who decides whether a particular topic, group, location, or cause is covered by moral or ethical principles? I addressed this issue in commenting on a 2015 paper by M. Brocx and V. Semeniuk, "The development of solar salt ponds along the Pilbara Coast, Western Australia - a coastline of global heritage significance used for industrial purposes". The first sentence of their abstract summarizes their view, "The Pilbara Coast in NW Australia stands unique as the most geologically/geomorphically diverse arid coast globally and, as such, it is a coastline of Global Significance." I was previously unaware of specif- 
ics of the Pilbara Coast and am unable to determine whether the Pilbara Coast deserves the protection Brocx and Semeniuk wish it had. But I strongly suspect that others disagree with Brocx's and Semeniuk's views and with equally good ethical reasons. It is a result of how different people rank different "good" outcomes (Abbott, 2016b).

\section{MORAL AND ETHICAL ANALYSIS}

Analysis of an ethical situation requires careful analysis employing the following:

- Identifying the ethical principle(s) involved.

- Discriminating between relevant and irrelevant facts.

- Being logical.

- Being objective.

- Being consistent - all similar cases must be treated the same way.

Discussion of and reflection on ethical case histories demonstrate that small differences in the relevant facts can lead to quite different conclusions. Consider the following examples:

Example 1: A geoscientist has prepared a structure contour map that is part of a project for a client. The geoscientist's project manager, who is also a geoscientist, reviews the map and concludes that the contours should be changed in a way that has the effect of making the project look better. Does the difference between the original and revised version of the structure contour map reflect (a) an effort to please the client or (b) a legitimate difference of professional opinion? What considerations would go into favoring alternative $a$ or $b$ ?

Example 2: A university professor has been retained as a private consultant on a project located several hours by car away from the university. During the same trip, the professor also does a field check of a graduate student's thesis area, which is located near the consulting project. The professor is permitted to drive a university vehicle to the graduate student's thesis area. Should the professor also drive the university vehicle to the private client's project site? If yes, should the university be reim- bursed for half the whole trip or just for the extra miles required to visit the client's site? If the university vehicle should not be taken to the client's project site, how should the professor get to the site? Should two separate trips be made or are there other solutions? Are there any other facts that would change your view of the situation?

The American Institute of Professional Geologists (2017a) has published a large number of articles and columns on professional ethics for over 20 years.

\section{DOES HAVING A CODE OF ETHICS REQUIRE DISCIPLINE?}

Most geoscience professional societies have educational and experience requirements for membership. These qualifications were among the reasons for organizing in the first place. Membership was a credential the public could look to for assuring competent work and honest appraisal of natural resource offerings. Abbott (2018) reviews the history and application of enforceable codes of geoscience ethics.

Once a professional organization has decided that it will have an enforceable code of ethics, it must determine which provisions of its code of ethics are ethical rules that cannot be violated and which are aspirational statements. Most professional societies have codes of ethics with both types of provisions, while state licensing boards and others will have codes of conduct containing only ethical rules.

Adoption of an enforceable Code of Ethics requires that disciplinary procedures be adopted. These disciplinary procedures should describe all of the processes of:

1. Review of allegations.

2. Initiation of an investigation.

3. Filing of formal charges.

4. Adjudication process.

5. Appellate process.

6. Describe the disciplinary sanctions that can be imposed.

7. Describe the rights of respondents.

8. Avoidance of conflicts of interest within the procedures.

9. Confidentiality of the proceedings. 
10. Reporting of violations to other organizations and regulators.

11. Publication of annual summaries of disciplinary activity.

Abbott (2018) contains detailed descriptions of these 11 activities, and the American Institute of Professional Geologists' (AIPG) Disciplinary Procedures (2015) provide an excellent example of such procedures. AIPG publishes an annually updated summary of its disciplinary activities (AIPG, 2017b) The Grievance and Disciplinary Procedures of the European Federation of Geologists (EFG) are contained in Regulation C2-Ver 5 (2010).

\section{REFERENCES}

Abbott D.M. Jr. (2004). Are scientific honesty and "best practices" in conflict?: European Geologist, No. 18, December 2004, p. 34-38; reprinted in The Professional Geologist, July-August 2005, p. 46-51.

Abbott D.M. Jr. (2007). Assuring the reliability of your sampling results: The Professional Geologist, November/December 2007, p. 33-38.

Abbott D.M. Jr. (2016a). USGS inorganic geochemical lab manipulated data and proving your data are accurate: The Professional Geologist, Professional Ethics \& Practices column 160, p. 31-32.

Abbott D.M. Jr. (2016b). Geoethics: The Professional Geologist, Professional Ethics \& Practices column 157, p. 32-33.

Abbott D.M. Jr. (2018), Brief history and application of enforceable professional geoscience ethics codes. In: Gunderson L.C., ed., Scientific integrity and ethics with applications to the geosciences: Special Publication American Geophysical Union, John Wiley and Sons, Inc., pp. (in press).

AIPG - American Institute of Professional Geologists (2015). Disciplinary Procedures: www.aipg.org/disciplinaryprocedures, accessed March 2017.

AIPG - American Institute of Professional Geologists (2017a). Professional ethics and practices topical index: www.aipg.org/codeofethics, accessed March 2017.
AIPG - American Institute of Professional Geologists (2017b). AIPG Disciplinary Procedure Actions 1989 through 2016: www.aipg.org/disciplinaryactions, accessed March 2017.

AGI - American Geoscience Institute (2015). Guidelines for Ethical Professional Conduct: www.americangeosciences.org/community / agi-guidelines-ethical-professionalconduct, accessed September 2017.

ASA - American Statistical Association (2016). Ethical guidelines for statistical practice: www.amstat.org/ASA/Your-

Career/Ethical-Guidelines-for-StatisticalPractice.aspx, accessed September 2017.

Brocx M. and Semeniuk V. (2015). The development of solar salt ponds along the Pilbara Coast, Western Australia - a coastline of global heritage significance used for industrial purposes. In: Peppoloni S. and Di Capua G., eds., Geoethics: the role and responsibility of geoscientists, Geological Society of London, Special Publication 419, p. 31-41.

Carter S.L. (1996). Integrity: Harper Perennial, $288 \mathrm{p}$.

EFG - European Federation of Geologists (2010). Grievance and disciplinary procedures, Regulation C2-Ver 5: http: / / eurogeologists.eu / statutesregulatio ns / C2, accessed March 2017.

EFG - European Federation of Geologists (2016). Code of Ethics, Regulation C1, Ver. 6: http: / / eurogeologists.eu/wpcontent / uploads / 2017 / 07 / Reg-C1-Ver-6Nov-2016.pdf, accessed September 2017.

Gert B. (2004). Common morality - deciding what to do: Oxford University Press, 179 p.

\footnotetext{
* AIPG-CPG, FGSL, EurGeol, FAusIMM
} 